\title{
Toward a unified view of time: Erwin W. Straus' phenomenological psychopathology of temporal experience
}

\author{
Marcin Moskalewicz $^{1,2,3}$ (D)
}

Published online: 26 January 2017

C) The Author(s) 2017. This article is published with open access at Springerlink.com

\begin{abstract}
The article covers Erwin W. Straus' (1891-1975) views on the problem of time and temporal experience in the context of psychopathology. Beside Straus' published scholarship, including his papers dealing exclusively with the subject of time, the sources utilized in this essay comprise several of Straus' unpublished manuscripts on temporality (all from the Erwin. W. Straus Archive, Simon Silverman Phenomenology Center, Duquesne University, USA), with the primary focus on the 1952 manuscript Temporal Horizons, which is discussed in greater detail and subsequently published for the first time in this journal. In the first part of the article, the author introduces what he considers to be the central tension of the whole of Straus' work on the issue of time, namely, the tension stemming from a dualistic account of time with its personal (experienced) and impersonal (clock time) dimensions. Interpretative developments of this tension are followed covering Straus' early German works and his late American scholarship. The author presents Straus' way of overcoming the dualistic account of time and his arguments in favour of what is termed here the "unified view of time". Of critical importance for the unified view is Straus' concept of "today", which is extensively commented upon. In the second part of the article, the author focuses on the psychopathological consequences of the unified view as seen by Straus. A clear-cut boundary between a normal and a psychotic experience of time is supposed to lie in breaking the bond between the personal and the impersonal orders of time, leading to a fundamental estrangement. This view, it is claimed, is already present in a nutshell in Straus' earliest work, and is elaborated upon later. In conclusion, both the merits and the weaknesses of Straus' account of temporality are presented. A major
\end{abstract}

Marcin Moskalewicz

moskalewicz@gmail.com

1 Faculty of Philosophy, University of Oxford, Oxford, UK

2 Department of Social Sciences, Poznan University of Medical Sciences, Poznan, Poland

3 Res Publica Foundation, Warsaw, Poland 
advantage is that Straus abstains from a dualistic conception of time and reappraises the often-devalued clock time. A fundamental drawback is that Straus does not venture to explore the pathological varieties of temporal experience and fails to specify the acknowledged differences between, on the one hand, psychotic elements in depressive disorders, and, on the other hand, such elements in schizophrenic disturbances.

Keywords Erwin W. Straus · Psychopathology · Lived time - Temporality · Temporal experience $\cdot$ Clock time $\cdot$ Psychotic experience $\cdot$ Today

\section{Introduction}

In this paper, I will focus upon the development of Erwin W. Straus' (1891-1975) views on the problem of time and temporal experience in the context of psychopathology. While it has been rightly claimed that the main theme around which Straus' work had centered was the lived movement - a subject encompassing such topics as upright posture, the horizon of meaning or awakenness (Eng 1976) - I will maintain that the subject of lived time was at least of equal importance. As a matter of fact, in the field of philosophical reflections on time in psychiatry, and especially, anthropological temporal preconditions of clinical psychopathology, Straus was no less than an innovator.

I will start by introducing what I consider to be the central tension of the whole of Straus' work on the issue of time, namely the tension between two seemingly mutually exclusive accounts of (normal) time - personal and clock time. I will then move to Straus' 1952 unpublished manuscript entitled Temporal Horizons, which is subsequently presented for the first time to readers. The importance of the manuscript lies in the fact that it most clearly explains Straus' own way out of the aforementioned tension and toward what I will term his unified view of time. The manuscript also presents the concept of "today", being of critical importance for the unified view of time in the most comprehensive way. I will then introduce Straus' older and later papers (including his unpublished manuscripts) ${ }^{1}$ in order to follow the interpretative developments of this tension more chronologically. Even if the subject of time was present in many of Straus' writings, there are several papers that deal with it exclusively, which would merit special attention. Next, I will focus upon Straus' account of a psychotic experience of time that originates in his unity view. In the final section of this essay, I will present both the merits and the weaknesses of Straus' phenomenological psychopathology of temporal experience.

\section{Temporal dualism}

Straus' pioneering work in an anthropological and phenomenological approach to psychiatry was focused upon disclosing normal human experience, which he considered a necessary epistemological precondition for assessing what is pathological.

\footnotetext{
${ }^{1}$ All unpublished papers discussed below are listed neither in Straus' official bibliography (Spicker 1977a), nor in Thornsten Passie's table on chronology of Straus' works on time (Passie 1995, p. 203).
} 
Accordingly, he believed that an outline of ordinary experience of time is the first step toward describing its pathological modifications.

However, any understanding of (normal) temporal experience suffers from a tension between its two possible and, seemingly, mutually exclusive accounts. The tension can already be noticed in Straus' early papers, but it becomes fully present in his later ones, and it is from the perspective of these that it will be presented here. ${ }^{2}$ Straus was using different - often, though not always, interchangeable - idioms to name these two accounts. Hence, on the one hand, there is the personal, immanent or existential time, and, on the other hand, the world, clock, calendar, public, objective or homogenous time (see table 1). These two accounts of time only vaguely mirror the distinction between what the analytical tradition (following John McTaggart) calls the A-series and the B-series time and the phenomenological tradition often characterized as immanent and clock time.

Straus' own way out of the dilemma was, what I propose to call, "the unified view of time" - that is, a view that overcomes the dualism of the two accounts while preserving the distinctive aspects of both. It is also the view that enabled Straus to conceptualize a genuine psychotic experience in temporal terms. Some hints toward such a unified view can already be inferred from Straus' early work in the 1920s and 1930s, but it was fully developed only through the 1950s and 1960s, alongside his shift in emphasis toward the existential importance of the previously underestimated clock time. I will claim that the changes in nomenclature that Straus was using at particular stages of his life imply shifts in emphasis on different aspects of the traditional dichotomy, while the 1952 manuscript entitled Temporal Horizons contains the most elaborate arguments in favour of fully overcoming the dualism of clock and personal time.

\section{Temporal Horizons manuscript and the concept of "today"}

With the goal of understanding the problem of disorientation in time in mental illness, Straus begins his 1952 manuscript with an analysis of normal, temporal experience - the first step toward describing its abnormal modifications. He starts with the classical texts of Augustine's Confessions and Aristotle's Physics, and moves to a critical comparison of Henri Bergson's dualistic view of time and Sigmund Freud's dualistic view of consciousness. These are, however, merely preliminary remarks for the principal part of the manuscript, in which Straus' thesis on the unity of any traditional dichotomy of time is presented. In this latter part, Straus describes clock and calendar time as human conceptual achievements and illustrates his thesis by a close analysis of the concept of "today".

Regarding the historical-philosophical part of his essay, St. Augustine's analysis serves as an introduction that outlines the mysteries and paradoxes of time-comprehension. Alongside Aristotle's view, the conception of Augustine is presented as an anticipation of Bergson's influential ideas from his Time and Free Will: An Essay on the Immediate Data of Consciousness on the duality of the duration of consciousness and homogenous time, yet,

\footnotetext{
${ }^{2}$ Straus was interested in temporality almost from the beginning of his career: he introduced his historical and temporal mode of thinking concerning the biological world in general in his habilitation work on the problem of individuality that appeared in 1926 (Straus 1926). At that time he was already familiar with St. Augustine's concept of time - one of utter importance for his later work and analyzed closely in the 1952 essay Temporal Horizons.
} 
Table 1 Two accounts of time in Straus' works

\begin{tabular}{|c|c|c|}
\hline Straus' work & Expression of the duali & sm in terms of: \\
\hline $\begin{array}{l}\text { Das Zeiterlebnis in der endogenen Depression und in der } \\
\text { psychopatischen Verstimmung } \\
\text { (Straus 1928) }\end{array}$ & $\begin{array}{l}\text { Personal time } \\
\text { Experience-immanent } \\
\text { time }\end{array}$ & $\begin{array}{l}\text { World time } \\
\text { Experience-transcending } \\
\text { time } \\
\text { Homogenous objective } \\
\text { time }\end{array}$ \\
\hline $\begin{array}{l}\text { Geschehnis und Erlebnis } \\
\text { (Straus 1978a) [1930] }\end{array}$ & $\begin{array}{l}\text { Experience-immanent } \\
\text { time }\end{array}$ & $\begin{array}{l}\text { Experience-transcending } \\
\text { time } \\
\text { Clock time }\end{array}$ \\
\hline $\begin{array}{l}\text { Vom Sinn der Sinne } \\
\text { (Straus 1978b) [1935] }\end{array}$ & $\begin{array}{l}\text { Lived time } \\
\text { Immediate temporality }\end{array}$ & $\begin{array}{l}\text { Objective time } \\
\text { World time }\end{array}$ \\
\hline $\begin{array}{l}\text { Psychotic Disorders } \\
\text { of Space and Time } \\
\text { (Straus 1946) }\end{array}$ & $\begin{array}{l}\text { Experienced time } \\
\text { Personal time }\end{array}$ & $\begin{array}{l}\text { Clock time } \\
\text { Chronometric time }\end{array}$ \\
\hline $\begin{array}{l}\text { Disorders of Personal Time in Depressive States } \\
\text { (Straus 1947) }\end{array}$ & Personal time & $\begin{array}{l}\text { Homogenous time } \\
\text { Cosmic time }\end{array}$ \\
\hline $\begin{array}{l}\text { On Obsession } \\
\text { (Straus 1948) }\end{array}$ & Historical time & Objective time \\
\hline $\begin{array}{l}\text { Remembering and Forgetting Clock Time } \\
\text { (Straus n.d.-a) }\end{array}$ & Immediate time & Objective time \\
\hline $\begin{array}{l}\text { Temporal Horizons } \\
\text { (Straus 1952) }\end{array}$ & $\begin{array}{l}\text { Duration } \\
\text { Psychological time } \\
\text { Temporal experience }\end{array}$ & $\begin{array}{l}\text { Homogenous time } \\
\text { Objective time } \\
\text { Clock and calendar time }\end{array}$ \\
\hline $\begin{array}{l}\text { Orientation in Time } \\
\text { (Straus 1956b) }\end{array}$ & $\begin{array}{l}\text { Sequence of natural } \\
\text { events } \\
\text { Historical time }\end{array}$ & $\begin{array}{l}\text { Public time } \\
\text { Clock and calendar time }\end{array}$ \\
\hline $\begin{array}{l}\text { Über Störungen der Zeiterleben bei seelischen } \\
\text { Erkrankungen } \\
\text { (Straus 1963b) }\end{array}$ & Lived time & Public time \\
\hline $\begin{array}{l}\text { Chronognosy and Chronopathy } \\
\text { (Straus 1964) }\end{array}$ & $\begin{array}{l}\text { Personal time } \\
\text { Chronology }\end{array}$ & $\begin{array}{l}\text { Superpersonal time } \\
\text { Chronometry }\end{array}$ \\
\hline $\begin{array}{l}\text { An Existential Approach to Time } \\
\text { (Straus 1967) }\end{array}$ & Existential time & Clock time \\
\hline $\begin{array}{l}\text { Time and Addiction } \\
\text { (Straus n.d.-c) }\end{array}$ & Personal present & Cosmic order of time \\
\hline
\end{tabular}

with an essential difference. It is not merely that the framework of reflections is different, with Augustine's being clearly Christian and theological, but that the metaphysics underlying this framework differs as well. Even though Augustine distinguishes two kinds of time: immediate time and its objective construction, he does not see them as opposing one another, which is clearly the view that Straus himself will prefer. There is no antithesis, which is very conspicuous in Bergson's work, where homogenous time is claimed to be secondary to duration. Straus goes as far as to assert that Bergson's approach, which depreciates objective time in a most uncompromising way, is in fact incongruent with an enlightened culture of reason. An analogical reproach concerns Freud's view on the duality of consciousness which Straus describes as strikingly similar to Bergson's - with Freud's unconsciousness supposedly representing what Bergson meant by the deep ego, and consciousness indicating what Bergson described as the superficial ego. Straus argues that both views are equally 
metaphysical in the sense that both assume a dichotomous structure, with one side being valued and the other unjustly depreciated. This is precisely where Augustine's, and Straus' own, view are supposed to differ, namely, in overcoming such a dichotomy and presenting a unified view.

The first step in achieving such a unified view involves re-appreciating objective time, by which Straus means time as constructed by our clocks and calendars. His clear point is that even though objective measures of time are guided by conventions, time itself is more than a convention. Put differently, there are various constructs that can be termed formal "languages of time" that are being used to comprehend it. Even if these languages may be incongruent with one another, this does not change the fundamental fact of the passage of time. In a similar vein, Straus overthrows cultural relativism that asserts existence of different temporal demands in various societies by arguing that even if respective powers of time differ between cultures, the basic human capacity to tell the time does not. Time-telling is both trivial and universal, and it is already present in the pre-scientific comprehension of the world. Simply put, construction of objective time is a universal human capacity.

The second step leading toward a unified view involves presenting inseparableness of immanent and objective time. Straus proceeds by taking advantage of the concept of "today", by far the most interesting of his ideas about time, nowhere commented upon more extensively than in the Temporal Horizons manuscript. Precisely through the concept of "today" Straus attempts to prove that the temporal dichotomy - he presents this distinction here in Bergsonian terms of duration and homogenous time - is false. The manner in which the double meaning of the concept of "today" is presented in this essay is also Straus' most balanced one in comparison with his later texts, as none of the extremes of this dichotomy has a priority here (compare section 6 below: The tension within a unity: the concept of "Today" in Straus' final papers).

"Today" belongs to immanent time because it is always someone's today. The concept designates pre-logical experience of presence and, just like the narrower concept of "now", has meaning only in a relationship to a speaking subject. "Today" is also undetermined and non-concrete: it does not indicate any precise day in the flow of days. At the same time, "today" is always some today and in this sense a determinant of objective time. It also has a symbolic character that, unlike the narrower concept of "now", is relatively independent of any subject. It indicates a certain extended conceptual whole, and in this sense it is determined and concrete.

What Straus wants to demonstrate is that, as a matter of fact, all the distinctions used above are artificial and do not bring us to the core of the phenomenon in question. In reality, there is just one time that is either personally or objectively apprehended. Both "times" are "subjective" in the sense that even clock time has an intersubjective dimension in that it is shared and also immanent to (normal) human experience. Yet, as I will argue, this view is not identical with Straus' earlier and later published works, since, as we shall see, the balance between the two sides has not always remained in such a clear equilibrium as it is presented in the Temporal Horizons manuscript. Straus' early German papers seem to favour the personal and undetermined aspects of temporal experience, while his later American papers and manuscripts lean more toward concrete and determined measures of clocks and calendars. Nevertheless, these changes are merely a matter of emphasis. Since, in Straus' opinion, we are dealing with two sides of the same coin, I will claim that we should regard the equilibrium of these two kinds of time as a proper standard of normal temporal experience in Straus' own view. 


\section{German period: the personal time}

It may seem that, in his early German works, Straus deals exclusively with the personal and undetermined aspects of temporal experience, but that is not exactly true. The major concern of Straus' early writings is that the scientific worldview excludes any qualitative aspects of lived human experience. In what is probably his most influential paper on the subject, Das Zeiterlebnis in der endogenen Depression und in der psychopatischen Verstimmung (Straus 1928), ${ }^{3}$ Straus introduces a crucial distinction between "personal time" that is immanent to every individual experience (Ich-Zeit) and "world time" (Welt-Zeit) that transcends it. The latter, also called "experience-transcending time" (Erlebnistranseunte Zeit), is not really a matter of Straus' focus. What he emphasizes instead is the personal time that is immanent to the inner life story - the innere Lebensgeschichte (a concept that Straus borrowed from Ludwig Binswanger). Such a personal time does not simply pass but may be actually growing or declining, and it is this growth or decline that bears importance for Straus' psychopathological insights.

It is important to note that Straus - unlike many philosophers - does not consider personal time as a merely mental phenomenon, it is rather a biologically grounded one. For Straus, personal time belongs to what has been called the "biological ontological" condition of experience (Moss 1981). Even though this view has been criticized for neglecting the more existential dimension of life, in the end Straus actually maintains that it is the immanent temporal experience that establishes the connection between biological function and a personal life story (Florig 2015). Therefore, only through a meaningful life story can biological time make sense as either growing or declining.

Straus' early insights on temporal personal becoming find their full elaboration in his book Geschehnis und Erlebnis (Event and Experience) published in German two years after his essay on depression (Straus 1978a, 1982) [1930]. As the book is highly critical of the physicalist model of time, which, according to Straus, is being utilized by all of his contemporary psychological theories, it only reinforces the impression that he is not particularly interested in clock time.

Straus' line of argument against "objective psychology" continues in his next book, Vom Sinn der Sinne (The Sense of the Senses) published five years later (Straus 1963a, 1978b). As a matter of fact, what here is labelled objective psychology is science itself. Straus claims that when one considers experience merely in objectified time, one loses the dimension of the future that is immanent to it. ${ }^{5}$

Even if it may seem that in his early German works Straus defends personal time against its mechanistic reduction, the tension between two kinds of time is already, implicitly present. Experience-transcending time or world time as measured by the clocks remains the unexplored, other side of the coin present in the background of

\footnotetext{
${ }^{3}$ Straus continued to refer to it and to read it, as his two personal library copies, underlined and annotated by himself, prove.

${ }^{4}$ In that matter Straus was following the distinction made by Richard Hönigswald, a neo-Kantian philosopher, presented in his book Die Grundlagen der Denkpsychologie, published in 1925.

${ }^{5}$ Straus acknowledges that objective psychology may actually deal with the dimensions of the past and of the present (both wholly absent from the pure, mechanistic notion of time, consisting merely of a continuum of earlier and later moments). Nevertheless, objective psychology presents the dimension of the past as merely the past time of having been experienced, and the dimension of the present as merely a point-like now, supposedly corresponding to physiological processes taking place within a body. In both cases, this is not time as it is being actually lived (Straus 1963a; Straus 1978b).
} 
Straus' reflections. Straus acknowledges that the phenomenal or the personal now being more than the point-like now of objective psychology - is always coordinated with clock time, even if it does not itself belong to it. Hence, Straus' opinion on the importance of clock time, which he developed in detail later on, already appears in the first German edition of Vom Sinn der Sinne (Straus 1978b) [1935]. Clock time, Straus states, is in fact so close to normal human experience, that "he, who condemns objective space and objective time condemns himself” (Straus 1963a, p. 359).

\section{American period: the clock turn}

In 1938, like so many Jewish intellectuals of his generation Straus moved to the United States. This change of culture would have profound consequences, not only for his private life, but also for his scholarship, and would soon leave traces on his professional interests in time. Straus' first American paper on temporal experience was originally presented to the Section on Neurology and Psychiatry at the Southern Medical Association's Annual Meeting in Miami in 1946, and appeared one year later as Disorders of Personal Time in Depressive States (Straus 1947). In this short but dense piece, Straus not only emphasizes some of his earlier insights on temporal experience, but also clarifies and somewhat modifies his earlier views. However, the spirit of this paper is still very "German" in the sense that Straus' interests lie primarily in what he continues to call the personal time. Still, in his 1948 book On Obsession, Straus presents objective time, not as a social and shared phenomenon, which will be the case with his later writings, but as impersonal and incommensurable with "historical time", to which the compulsive symptoms are supposed to belong (Straus 1948).

In Straus' slightly later papers it is easy to see a change in focus toward objective measures of time - particularly calendars - from an earlier emphasis on subjective temporal experiences. But, by no means does Straus contradict his earlier insights here. Rather, he explores and presents in greater detail their previously undeveloped counterpart. Consequently, the theme of orientation and disorientation in clock time becomes the main subject of Straus' work of the 1950s and 1960s on temporality. Intriguingly, Straus' novel views on temporality parallel his growing into the culture of post-World War II America, with its rigorous social temporality based upon the clock.

Straus' first unpublished paper from this period, Remembering and Forgetting. Clock Time, can be dated to the late 1940s and early 1950s (Straus, n.d.-a). ${ }^{6}$ The opposition between the two types of time is phrased here in terms of immediate and objective time. The latter concept now represents the former idea of experiencetranscending time and points toward clocks and calendars as providing us with a shared, conceptual temporal framework. During this time Straus also worked on his paradigmatic Temporal Horizons manuscript, whose extraordinary importance, as we have seen, lies in his most elaborate presentation of the argument on the falseness of any dichotomy of immediate and objective time. Later in the same year, Straus wrote a paper entitled Orientation in Time, which exists in several manuscript versions dating

\footnotetext{
${ }^{6}$ A talk under this title was given by Straus at least twice: at a Boston Psychiatric Society meeting in October 1949 and at a Neurological Society gathering in Frankfurt am Main in June 1953.
} 
from August to September 1956 (Straus 1956b). In this piece, also representing his new shift of interests, Straus considers clocks and calendars as providing intersubjective, conceptual order for subjective orientation in what he now calls a public time. Straus conceives public time as a cultural artifact that provides the whole units of time (such as months), which are never given in direct experience. These whole units enable situating any given particulars of experience within the larger, directly inaccessible abstract structures. ${ }^{7}$

\section{The tension within a unity: the concept of "Today" in Straus' final papers}

These themes and reflections, even if mostly unpublished, were taken advantage of later and utilized in Straus' last published papers on the subject of time. Though Straus maintained his interest in temporal experience, presenting papers at conferences and giving talks, only three more explicit manuscripts on the subject appeared in print during his lifetime.

The first of these - Über Störungen der Zeiterleben bei seelischen Erkrankungen was presented in June 1960 at the 78th Meeting of Southwest German Neurologists and Psychiatrists in Baden Baden, and published in 1963 (Straus 1963b). In this short piece, Straus considers temporal orientation as a social act involving what he continues to call a public time, and criticizes its traditional devaluation in philosophical reflections. The norm of regular human temporal experience is presented here in the form of a hermeneutic circle between the now moments and abstract temporal wholes, which is facilitated by the concept of "today". "Today" is an elementary type of a whole - one that must be comprehended in order to position particular moments of the day within a larger scheme. Any act of temporal orientation is social and requires combining one's "today" with the public time of others - its failure leads to abnormal social isolation.

Nevertheless, in Über Störungen der Zeiterleben, "today" appears as slightly closer to what Straus had previously called personal time than in the Temporal Horizons manuscript. For example, a sufferer of amnesia, who is able to comprehend "today" as his own and personal, may still be lost in the social time and, in consequence, alienated. On the other hand, in a paper roughly from the same time, originally published in 1961 and entitled Norm and Pathology of I-World Relations (Straus 1966), Straus uses the concept of "today" more in the sense of clock time, that is, as an abstract whole, an objectified extension of personal time. "Today" is supposed to represent a non-present whole, that is, a whole never given in direct experience, one that is conceptual and symbolic in nature. Being able to comprehend such a basic abstract whole is a condition of possibility of orienting oneself in time.

Similarly, in the paper Chronognosy and Chronopathy of 1964, the concept of "today" is understood as a scheme never given in direct experience, and, unlike the more narrow concept of "now", providing a conceptual comprehension of the whole, analogical to the hands of a clock conducting a full cycle of twenty-four hours (Straus 1964). Such "today" becomes concretized through larger schemes of calendar time that constitute a despotic "superpersonal" order with which we must all comply. Straus also claims that subordination of our lived moments to the calendar - to the social temporal

\footnotetext{
${ }^{7}$ The theme of the calendar was also explored in Straus' undated notes under the title The Calendar as a System of Signs (Straus n.d.-b).
} 
logos - is healthy, whereas impairment of the ability to abstract from these lived moments leads to a temporal disorientation. While in this paper Straus does not comment upon the immediate aspects of "today", he makes clear that both "now" and "today" are meaningless when detached from the vantage point of a particular speaker.

The concept of "today" appears also in Straus' last written and unpublished paper on time entitled Time and Addiction (Straus n.d.-c). Straus again emphasizes that the norm of temporal experience in general - the norm that is supposed to lurk behind pathological modifications entailed by drugs - consists in pre-reflective understanding of the concepts of both "now" and "today". The latter thus appears as closer to indeterminate temporal presence. Both concepts have no meaning when appropriated merely abstractly and detached from the presence of a speaker and a listener. The tension within the concept of "today" notwithstanding, through this final statement Straus is endorsing the unified view of time as presented above in his published work.

In conclusion, even if the concept of today has qualities pertaining both to immanent (personal) and clock (public) time, it can be used with an emphasis being put on either of these meanings. Today is a symbolic, calendar-like concept but it does not make sense without the presence of a speaker. On the other hand, comprehending today in the sense of an extended conceptual whole is apparently not enough for an orientation in time, for it must be paired with subordinating such an extension to a larger and more concrete public temporal order of the calendar.

\section{The tension within a unity: the priority of personal time}

Ultimately, and not surprisingly, immanent and clock time are not simply equally important. Indeed, Straus subordinates homogenous to personal time long before his turn toward the clock. In his first American paper on depression, Straus states that not only is there a crucial distinction between the perception of time understood as a series of impressions (as studied by all kinds of experimental scientists) and the experience of time in the phenomenological sense, but also that such a series of impressions is necessarily based upon the experience of time (Straus 1947). ${ }^{9}$ Thus, Straus' position is far cry from granting clock time any existence separate from its personal apprehension. In spite of his clock turn, in several papers from the 1950s and 1960s Straus ascribes a priority to personal time.

In July 1956, in a paper given for the University of Kentucky Philosophy Club, Straus spoke of the temporal extension of the mind that enables comprehension of time as such, or "a timeless order of time", through objectified schemes of the clock, such as minutes and hours. He metaphorically calls this extension "the watershed between past

\footnotetext{
${ }^{8}$ The manuscript is six pages long and exists in two unfinished and unpublished versions. It was certainly conceived after 1968, and possibly even after 1971. The manuscript testifies to Straus' continuous effort to understand time as well as to his late interests in the impact of marihuana and hashish upon temporal experience, thus in a way reviving his early scientific interests in addictions (Straus 1919).

9 On 3rd May 1956, during the annual meeting of the American Psychiatric Association, Straus participated in a discussion on time sense for short intervals in depressed and schizophrenic patients (Straus 1956a). Then, he expressed his doubts about whether experimental time estimation tasks could reach to the core of the problem of temporal experience. In his view, qualitative experiences of personal time will influence any objective estimations of time perception in an indeterminate way so that we may never take hold of an objective time in a pure way, as separated from the person.
} 
and future" - one that is a condition of possibility of any schematic comprehension of the "timeless order" (Straus 1956c). This view is most extensively discussed in the already-mentioned Chronognosy and Chronopathy paper, which was presented at the first of five Lexington conferences on pure and applied phenomenology in 1963 and published one year later (Straus 1964). It is certainly not only the longest, but also the most comprehensive of all of Straus' papers on time, providing a sort of summary of his lifelong reflections on temporality. Straus intended to describe psychological preconditions of any possibility of the process of measurement of a series of impressions. Yet, what he actually defines are certainly not only simple psychological preconditions (such as sensory experience), but also transcendental conditions of possibility. ${ }^{10}$

As Straus maintains, even the simplest act of measuring time brings together two series of events - one of which is determined and scaled (for example, the stopwatch hand or movement of the sun in the sky) and the second which is not (for example, cooking a stew or running a race) - in such a way that the simultaneity of both series is established through the actuality of the spectator's position. Only the spectator is capable of visualizing both series in retrospection, thus going against the normal flow of time toward the future. Accordingly, not only an abstract transformation of sensory experience takes place, with conceptual measurements imposing beginnings and endings and transcending the realm of what is directly present, but also such a transformation is conditioned by a prior temporal extension of the spectator's mind.

Straus presents the same view in his last published paper on time - An Existential Approach to Time from 1967 (Straus 1967). The epistemological hierarchy between the two orders is clear: there would be no superpersonal order of time (clock time) without the personal order of time, while simultaneously the personal order derives its position from the clock and calendar distinctions. In a normal, daily life situation, the two orders are synchronized to the extent of not being distinguishable - they remain in "harmony", as Straus claimed in his 1928 article on depression (compare the following section).

\section{Psychopathological consequences}

Straus' unified view of time does not represent every possible human experience. Its clinical importance becomes clear once we have a look at Straus' major assertions concerning the essential features of temporal disturbances in mental disorders. Straus claims that it is not unusual for many people to feel disoriented in time, and that the difference between normal and abnormal orientation is one of degree (Straus 1956b). Nevertheless, there is a clear-cut boundary between abnormal lived time experiences such as suffering from compulsive repetitions and the concomitant loss of the continuity of life (Straus 1938, 1948) - and a full-fledged psychotic experience of time. The core of the latter supposedly consists in breaking the invisible bond between the personal and the superpersonal orders of time. A split between the two sides of a normally unified phenomenon allegedly leads to a profound estrangement.

In the following part of this paper, I will present and discuss Straus' view on the broken bond, a view that is most clearly exemplified by an interview with a depressive

\footnotetext{
${ }^{10}$ Given Straus' own reservations toward a transcendental way of reasoning in the Kantian tradition (Spicker 1977 b) it might be safer to speak of lived-bodily conditions, but, to be sure, considered as no less universal ones.
} 
psychotic patient included in the 1952 manuscript Temporal Horizons. I will argue that this view was already present in a nutshell in Straus' earliest work on abnormal temporal experience in depression and became elaborated upon later.

While following variations of Straus' core thought, I will claim that his conception suffers from a fundamental drawback. Precisely by trying to grasp the phenomenal essence of the psychotic temporal estrangement, Straus fails to specify the acknowledged differences between, on the one hand, psychotic elements in depressive disorders, and such elements in schizophrenic disturbances on the other (Fuchs 2005, 2013, 2015; Kupke 2009; Stanghellini et al. 2016).

In his first paper on depression (Straus 1928), recognizing the importance of lived time for psychiatry, Straus introduces a criterion enabling him to distinguish normal human becoming from what he considers its unhealthy modification. As was already noticed, both are based upon biological potential being expressed and experienced temporarily, either as a progressive development or as a regressive inhibition. In a healthy, normal situation, the future is supposed to be lived as undetermined, open and full of possibilities for action. Crucially, in such a situation, Straus claims that there is a balance and a "harmony" between what he then calls immanent and experience-transcending time. An implication for understanding pathological states is that when this balance is lost in favour of the past, we are dealing with depressive states, and when it is lost in favour of the future, with euphoric states. Straus thus focuses on the subjective experiences of the dimensions of the past and the future, claiming that in depressive delusion the latter is viewed as being determined by the former. In the extreme case of what Straus calls an endogenic (that is, somatically grounded) depression, a total inhibition of vital temporal becoming supposedly takes place. While it may seem that Straus discusses here merely the experience of immanent time, and, indeed, he barely touches upon the theme of the clock, the idea of a harmony between the two times points toward the ideas that he developed later.

Straus presents an almost identical conception in his 1947 Disorders of Personal Time in Depressive States (Straus 1947). Most importantly, even if briefly, he speaks about the possibility of discordance between personal and objective time. Again, this goes beyond simple lagging behind the clock or accelerating in regards to it, and can be experienced as unreality or the vanishing of time. It is supposed to be a situation of being in direct opposition to any attunement with the world and coordination of the now with clock time that Straus described in his 1935 book Vom Sinn der Sinne in non-pathological terms.

Straus explores his claim on the relevance of the relationship between the personal and the superpersonal orders of time in greatest detail in a manuscript entitled Psychotic disorders of space and time, written in June 1946 (Straus 1946). His intention is to show how the decomposition of the unified experience leads to depersonalization and to a loss of the common world. In this paper, such decomposition is explicitly presented as a break between the personal now and world time, whereas the concept of "today" as we have already seen, being of critical importance later on - does not yet appear.

Finally, Straus' core idea is exemplified in the 1952 interview that forms the last part of his Temporal Horizons manuscript. The presented case is supposedly representative of many instances of disintegration of time and illustrates Straus' point that it is not the impairment of the ability to abstract from personal time that characterizes psychotic experience (as this ability, and, therefore, orientation in time is still conceptually 
possible), but the damage of the invisible connection between personal and objective time. We may notice that the interviewed patient experiences his own indeterminate presence in the moment. He is simultaneously capable of all sorts of calendar-like calculations and assessing the temporal distance regarding both past and future. Yet, the two times do not come together and his self does not somehow fit into those objectifying temporal schemes. In other words, even if the patient is capable of understanding "today" abstractly, it does not have any meaning for him as he is unable to execute it as his own. The breaking of the bond thus illustrates the boundary phenomenon of a loss of reality, which thus appears as an effect of co-existence and co-relation of the two aspects of time, whereas their separation allegedly gives an effect of unreality and alienation. ${ }^{11}$

\section{Conclusion: an unfinished project}

A lack of precise distinctions that would enable us to differentiate between the varieties of abnormal time experiences in different mental disorders is characteristic of Straus' early and middle papers. On the other hand, his late papers, being precise in their descriptions of normal time experience, disappoint mostly by not incorporating the subject matter of psychopathology to a sufficient extent. It seems as if Straus, despite his own intentions, moved away from the psychopathology of time later in his life.

In his 1963 piece that was supposed to be concerned with temporal disorientation in amnesia, Straus gives the norms more attention than the pathologies (Straus 1963b). His conclusion regarding the latter is confined to the claim that when "today" and public time split, social isolation follows. The same theme of the impossibility of transgressing the lived moment, the lived now, through any conceptual order of time (that is, establishing temporal part-whole relationship) as characteristic of a mentally ill person is also discussed in his work from roughly the same time (Straus, Natanson, and Ey 1969, published originally in German in 1963), nonetheless nothing more than we have already heard of the subject is said.

The most disappointing fact is that Straus' Chronognosy and chronopathy paper does not actually deal with the phenomenon of chronopathy - officially due to a lack of time at his original conference talk - but again focuses on the preconditions of normal temporal functioning. Straus' conclusion, which is limited to the statement that an inability to abstract from lived presence through the schemes of the calendar leads to temporal disorientation, is simply left without any further elaboration.

Analogous disappointment concerns Straus' last article on temporality from 1967 (Straus 1967). ${ }^{12}$ In January 1966, Straus took part in a conference at the New York

\footnotetext{
${ }^{11}$ The impact of Straus' reflections on this subject can be seen today in a more sophisticated conception of Thomas Fuchs, which takes advantage of the idea of intersubjective synchronicity (Fuchs also speaks of “fundamental co-temporality"). In Fuchs' view, depressive retardation and manic acceleration are more than simple subjective experiences of clock time slowing down or speeding up, as they relate to world time of both biological and social processes of various simultaneities (Fuchs 2001). On the other hand, the disturbances of temporal experience in schizophrenia consist of implicit temporal fragmentation rather than simple, even if radical, asynchrony between personal and world time (Fuchs 2013, 2015).

12 The paper reappeared unrevised in the German translation by Viktor Emil von Gebsattel one year later (Straus 1968). Its psychopathological part, mostly repeating the already-known theses, is devoted to an analysis of an old case study of von Gebsattel's patient suffering with chronophobia, originally published in 1928 (Gebsattel, 1954).
} 
Academy of Sciences entitled "Interdisciplinary perspectives of time". He intended to limit his theoretical considerations and to speak about pathologies of personal time in cases of misery, voyeurism and senile amnesia (Straus 1965), but it seems as though he did not fulfill this promise (at least not in the published version of his original talk). The final paper that appeared in the Annals of New York Academy of Sciences is concerned much more with anthropology than with psychopathology, as indeed is most of Straus' work on temporal experience.

There are unquestionable merits in Straus' reflections on temporality in the context of psychopathology. The major one is that Straus not only takes creative advantage of the phenomenological concept of lived temporality, but also abstains from any dualistic conception of time. As several of his American papers after the postulated clock turn make clear, the often devalued clock and calendar time receives from Straus a fresh appraisal as a necessary counterpart of any lived experience. Abstraction from lived presence - even as simple as saying "today" - requires a conceptual scheme (or a frame of reference, sufficiently as rudimentary as the movement of the sun on the horizon), and such an abstraction constitutes a constant counterpart to normally lived time. In other words, in order to have a lived past and future beyond a simple retention and protention (or implicit temporality), that is, to have an existential past and future with the sense of one's self being temporarily extended, one needs some sort of objective measure of time.

The chief limitation of Straus' position, however, is that he does not venture to explore the pathological varieties of temporal experience, restraining his view of the psychotic experience of time to the idea of a break between personal and impersonal orders. Straus' core idea of the unity of the temporal experience and its psychotic breakdown is always illustrated by cases of depressive patients, whereas its ambition seems to be to reveal something essential about psychotic experience as such. This cannot but leave the reader with a sense of unfulfilment. If the connection between world time and existential time is one of degree, as Thomas Fuchs shows in detail (Fuchs 2001, 2013, 2015), then precisely how does it get fully broken? The depersonalized patient interviewed in the Temporal Horizons is clearly more than simply desynchronized. Time does not just pass too quickly for him to catch up with it, his existential temporality suffers from a profound transfiguration. On the other hand, when a depressed or a manic patient, even in the state of psychosis, is able to follow certain rules of clock time and, for example, remembers to come on time to his meeting with a doctor, is the bond in question already broken or merely loosened? If one knows what time and date it is at a given moment, as well as comprehends the calendar time of yesterday and tomorrow - meaning that one is well oriented in clock time, while, at the same time, one is unable to experience tomorrow in an existential sense as his or her tomorrow - then what exactly is the connection in question? Is it not that in a boundary, pathological situation, one more severe than a modification of temporal becoming, the passage of existential time itself is lost? One might then find oneself "frozen" in time despite the fact that clock time is still passing (Moskalewicz 2016). Moreover, one can still be aware of the passage of clock time, yet one's own self exists in a temporal void or even comes to a standstill. In other words, while existential temporality is lost, clock time remains, and one is still potentially able to orient oneself in abstract time and in social temporal surroundings. 
If this comes close to Straus' ultimate point, then the latter would certainly profit from a more elaborate description of details, especially from an explanation of the differences between a deformation and a breakdown of the connection between personal and clock time. Again, if one is able to arrive for a meeting tomorrow at an exact hour, but remains unable to plan one's own personal future in the present, then where exactly is this mysterious bond lost? In this respect, Straus is particularly unsuccessful in specifying the differences between psychotic elements in depressive and compulsive disorders, and such elements in schizophrenic disturbances, which he does not comment upon at all. Secondly, Straus fails to indicate the differences between, on the one hand, a situation in which clock time and lived temporal presence are taken apart, but the ability to abstract from the lived now and orient oneself in time stays intact, and, on the other hand, a presumably worse situation, in which any relationship to clock time, and hence both temporalities, is fully lost. Straus himself does not seem to be content with his claims. Rather, he remains unsure and does not publish all of his research on this subject.

As far as the question of temporal experience is concerned, early Straus, writing in German, was mostly interested in the problem of - supposedly biologically grounded inhibition of temporal becoming in depressive states. Later on, after what has been described here as his "clock turn", Straus became more and more involved with the subject of temporal orientation and disorientation within the clock and calendar schemes. Finally, increasing attention to clock time led him toward reconsidering the conditions of possibility of measuring time in a more philosophical way. Altogether, Straus' views developed considerably, but they have never contradicted one another. Rather, at different stages of his career Straus was addressing different aspects of the traditional temporal dichotomy, and was consistently developing his own unified view of time. Nevertheless, Straus' ideas on the essential features of a psychotic experience of time remain limited to some instances of depression, and it must be left to others to fully develop his argument into a comprehensive phenomenological psychopathology of temporal experience.

Acknowledgements Open access funding provided by University of Oxford. The paper was written during a fellowship at the Collegium Helveticum at ETH Zurich/ University of Zurich, Switzerland, funded by the EURIAS Fellowship Programme and the European Commission (Marie-Sklodowska-Curie Actions COFUND Programme - FP7) and completed during Fulbright Fellowship at Texas A\&M Health Science Center, USA. Research in Erwin W. Straus Archive was funded by Polish National Science Center (grant No. NCN 2011/01/D/HS1/04262). I would like to thank Michael A. Schwartz and members of the History of Medicine Section at the University of Zurich for their useful comments to the first draft of this paper.

Open Access This article is distributed under the terms of the Creative Commons Attribution 4.0 International License (http://creativecommons.org/licenses/by/4.0/), which permits unrestricted use, distribution, and reproduction in any medium, provided you give appropriate credit to the original author(s) and the source, provide a link to the Creative Commons license, and indicate if changes were made.

\section{References}

Eng, E. (1976). Locating Erwin Straus. Journal of Phenomenological Psychology, 7(1), 1-14.

Florig, O. (2015). Zeit, Unmittelbarkeit und Geist: Straus' and Theunissens Deutung des Zeiterlebens in der endogenen Depression. In T. Breyer, T. Fuchs, \& A. Holzhey-Kunz (Eds.), Ludwig Binswanger und 
Erwin Straus. Beitraege zur psychiatrischen Phaenomenologie (pp. 197-210). Verlag Karl Alber Freiburg: Muenchen.

Fuchs, T. (2001). Melancholia as a desynchronization towards a psychopathology of interpersonal time. Psychopathology, 34, 179-186.

Fuchs, T. (2005). Implicit and explicit temporality. Philosophy, Psychiatry, \& Psychology, 12(3), 195-198.

Fuchs, T. (2013). Temporality and psychopathology. Phenomenology and the Cognitive Sciences, 12(1), 75-104.

Fuchs, T. (2015). Zeiterfahrung in Gesundheit und Krankheit. Psychotherapeut, 60, 102-109.

von Gebsattel, V. E. F. (1954). Prolegomena einer Medizinischen Anthropologie. Berlin, Göttingen, Heidelberg: Springer.

Kupke, C. (2009). Der Begrif Zeit in der Psychopathologie. Berlin: Parodos.

Moskalewicz, M. (2016). Disturbed temporalities. Insights from phenomenological psychiatry. Time \& Society, 25(2), 234-252.

Moss, D. (1981). Erwin straus and the problem of individuality. Human Studies, 4, 49-65.

Passie, T. (1995). Phänomenologisch-anthropologische Psychiatrie und Psychologie: eine Studie über den "Wengener Kreis": Binswanger, Minkowski, von Gebsattel, Straus. Hürtgenwald: G. Pressler.

Spicker, S. F. (1977a). Bibliography of the works of Erwin W. Straus. In H. T. Engelhardt Jr. \& S. F. Spicker (Eds.), Mental health: philosophical perspectives (pp. 157-167). Dordrecht: D. Reidel Publishing Company.

Spicker, S. F. (1977b). The Psychiatrist as Philosopher. Gewidmet Erwin W. Straus, M.D., PH.D. (h.c.), LL.D. (h.c.) (October 11, 1891 - May 20, 1975). In Mental Health: Philosophical Perspectives (pp. 143-155). Dordrecht: D. Reidel Publishing Company.

Stanghellini, G., Ballerini, M., Presenza, S., Mancini, M., Raballo, A., Blasi, S., \& Cutting, J. (2016). Psychopathology of lived time: abnormal time experience in persons with schizophrenia. Schizophrenia Bulletin, 42(1), 45-55.

Straus, E. (n.d.-a). Remembering and Forgetting: Clock Time (date unknown). Erwin W. Straus Archive, Simon Silverman Phenomenology Center, Duquesne University, USA, FF 131.

Straus, E. (n.d.-b). The Calendar as a System of Signs (date unknown). Erwin W. Straus Archive, Simon Silverman Phenomenology Center, Duquesne University, USA, FF 140.

Straus, E. (n.d.-c). Time and Addiction (date unknown). Erwin W. Straus Archive, Simon Silverman Phenomenology Center, Duquesne University, USA, FF40.

Straus, E. (1919). Zur Pathogenese des chronischen Morphinismus. Monatsschrift Für Psychiatrie Und Neurologie, XLVI, 1-20.

Straus, E. (1926). Das Problem der Individualität. In T. Brughsch \& F. H. Lewy (Eds.), Die Biologie der Person: Ein Handbuch der allgemeinen und speziellen Konstitutionslehre (Vol. I, pp. 25-234). Berlin, Vienna: Urban \& Schwarzenberg.

Straus, E. (1928). Das Zeiterlebnis in der endogenen Depression und in der psychopatischen Verstimmung. Monatsschrift Für Psychiatrie Und Neurologie, LXVIII, 640-656.

Straus, E. (1938). Ein Beitrag zur Pathologie der Zwangserscheinungen. Monatsschrift Für Psychiatrie Und Neurologie, 98(2), 82-101.

Straus, E. (1946). Psychotic Disorders of Space and Time. Erwin W. Straus Archive, Simon Silverman Phenomenology Center, Duquesne University, USA, FF 143.

Straus, E. (1947). Disorders of personal time in depressive states. Southern Medical Journal, 40(3), $254-259$.

Straus, E. (1948). On obsession. A clinical and methodological study. New York: Coolidge Foundation.

Straus, E. (1952). Temporal Horizons, Manuscript 1. Erwin W. Straus Archive, Simon Silverman Phenomenology Center, Duquesne University, USA, FF 137.

Straus, E. (1956a). Discussion of: The Time Sense for Short Intervals: preliminary observations in depressed and schizophrenic patients. Erwin W. Straus Archive, Simon Silverman Phenomenology Center, Duquesne University, USA, FF 140.

Straus, E. (1956b). Orientation in Time. Erwin W. Straus Archive, Simon Silverman Phenomenology Center, Duquesne University, USA, FF 140.

Straus, E. (1956c). Untitled paper for Univeristy of Kentucky Philosophy Club. Erwin W. Straus Archive, Simon Silverman Phenomenology Center, Duquesne University, USA, FF 140.

Straus, E. (1963a). The Primary World of Senses. A Vindication of Sensory Experience. (J. Needleman, Trans.). London: The Free Press of Glencoe, Collier-Macmillan Limited.

Straus, E. (1963b). Ueber Stoerungen des Zeiterlebens bei seelischen Erkrankungen. In G. Schaltenbrand (Ed.), Zeit in nervenaerztlicher Sicht. Vortraege des Suedwestdeutschen Neurologenkongresses, Pfingsten 1960 in Baden-Baden (pp. 14-16). Stuttgart: Ferdinand Enke Verlag. 
Straus, E. (1964). Chronognosy and chronopathy. In E. Straus (Ed.), Phenomenology: pure and applied (pp. 142-165). Pittsburgh: Duquesne University Press.

Straus, E. (1965). Time Conference (abstract). Erwin W. Straus Archive, Simon Silverman Phenomenology Center, Duquesne University, USA, FF 132.

Straus, E. (1966). Phenomenological Psychology. (E. Eng, Trans.). New York: Basic Books.

Straus, E. (1967). An existential approach to time. Annals of the New York Academy of Sciences, $138(2), 759-766$.

Straus, E. (1968). Zeit in existentieller Sicht. Jahrbuch Für Psychologie, Psychotherapie Und Medizinische Anthropologie, 16(1/2), 1-8.

Straus, E. (1978a). Geschehnis und Erlebnis. Zugleich eine historiologische Deutung des psychischen Traumas und der Renten-Neurose. Berlin, Heidelberg, New York: Springer.

Straus, E. (1978b). Vom Sinn der Sinne. Ein Beitrag zur Grundlegung der Psychologie. Berlin, Heidelberg, New York: Springer.

Straus, E. (1982). Man, Time and World. Two Contributions to Anthropological Psychology. (D. Moss, Trans.). Pittsburgh: Duquesne University Press.

Straus, E., Natanson, M., \& Ey, H. (1969). Psychiatry and philosophy. New York: Springer. 